\title{
Eksplorasi Serat Nanas dengan Aplikasi
}

\section{Sulam Sashiko}

\author{
Nabila Fasza \\ Program Studi Kriya Tekstil, Institut Teknologi Bandung
}

\begin{abstract}
Indonesia is a tropical country that has wide variety of flora and fauna. Various kind of plants are used for many needs. Fiber is an important crop that can be used by human after food crops. Beside the fruit is harvested for consumption, pineapple plant left a lot of leaf waste because after two to three harvest time, the old plant will be replace with new plants. This research aims to exploit pineapple fiber as an alternative raw material for textile by applying Sashiko embroidery on the exploration results of pineapple fiber. Design development is done with pineapple fibers exploration by using mango leaves as natural dye and Sashiko embroidery as their surface design. Sashiko embroidery created ornaments that can be used as an aesthetic element in the field of fabric. Sashiko embroidery application on the exploration of pineapple fiber is expected to raise the aesthetic value of order and pineapple fiber with a new structure that is intended for fesyen products.
\end{abstract}

Keywords: natural dyes, natural fibres, pineapples fibre, Sashiko.

\section{PENDAHULUAN}

Indonesia merupakan negara tropis yang memiliki beraneka macam flora yang berlimpah. Berbagai jenis tanaman digunakan untuk banyak kebutuhan. Tanaman serat merupakan tanaman penting yang dapat dimanfaatkan oleh manusia setelah tanaman pangan. Tanaman serat memiliki banyak fungsi seperti bahan baku kertas, tekstil maupun sebagai komposit. Namun potensi tanaman serat alam di Indonesia sebagai negara tropis belum dimanfaatkan secara optimal.
Disebutkan oleh Kirby dan Doraiswarmy, dkk., dalam Hidayat (2008), salah satu tanaman serat yang memiliki potensi untuk dikembangkan yaitu daun-daun tanaman nanas (Ananas Cosmosus). Tanaman nanas termasuk famili Bromeliaceae, pada umumnya termasuk jenis tanaman semusim. Bentuk daun nanas menyerupai pedang yang meruncing diujungnya dengan warna hijau kehitaman dan pada tepi daun terdapat duri yang tajam. Tergantung dari spesies atau varietas tanaman, panjang daun nanas berkisar antara 55 sampai $75 \mathrm{~cm}$ dengan lebar 3,1 sampai $5,3 \mathrm{~cm}$ dan tebal daun antara 0,18 
sampai $0,27 \mathrm{~cm}$. Di samping spesies atau varietas nanas, jarak tanam dan intensitas sinar matahari akan mempengaruhi terhadap pertumbuhan panjang daun dan sifat atau karakteristik dari serat yang dihasilkan. Intensitas sinar matahari yang tidak terlalu banyak (sebagian terlindung) pada umumnya akan menghasilkan serat yang kuat, halus, dan mirip sutera.

Selain diambil buahnya untuk dikonsumsi, tanaman nanas menyisakan banyak limbah daun karena setelah dua hingga tiga kali panen tanaman ini akan diganti dengan tanaman baru. Pada umumnya limbah daun nanas dikembalikan ke lahan untuk digunakan sebagai pupuk. Namun kini limbah tersebut mulai banyak diolah untuk diambil seratnya yang kemudian oleh perajin di Pekalongan, Pemalang, Cirebon, Yogyakarta, hingga di Sumatera diolah lagi menjadi berbagai jenis kerajinan. Meskipun telah digunakan sebagai produk kerajinan, pengembangan desain serat nanas ini masih sangat terbatas.

Pengembangan desain dilakukan dengan eksplorasi serat nanas dan pengaplikasian sulam Sashiko sebagai reka latarnya. Sashiko adalah teknik menjahit tradisional Jepang yang telah digunakan untuk menggabungkan beberapa lapisan kain sejak abad ke18. Penggabungan beberapa lapisan kain menggunakan Sashiko ini bertujuan untuk membuat pakaian lebih kuat dan tahan lama karena harga kain pada saat itu tidak tejangkau oleh para pekerja di sana. Jahit sulam Sashiko membentuk ornamen yang dapat dijadikan sebagai elemen estetis pada bidang kain.

Rancangan produk ini ditujukan bagi para wanita yang mengerti dunia fesyen dan peduli terhadap isu lingkungan. Pengaplikasian sulam Sashiko pada eksplorasi serat nanas ini diharapkan dapat mengangkat nilai guna dan nilai estetis serat nanas yang diperuntukan untuk produk fesyen.

Isu-isu yang harus diperhatikan ketika meneliti tentang Consumer behaviour adalah psikologi tentang bagaimana cara berpikir, perasaan, alasan, dan memilih antara berbagai alternatif seorang konsumen, psikologi bagaimana konsumen akan dipengaruhi oleh lingkungannya (budaya, keluarga, tanda dan media), kebiasaan konsumen ketika berbelanja dan membuat keputusan marketing, pengetahuan konsumen yang mempunyai limit, bagaimana strategi keputusan dan motivasi konsumen berbeda pada produk yang berbeda.

\section{METODE PENELITIAN}

Metode penelitian dilakukan dengan melakukan pengembangan desain melalui eksplorasi serat nanas dan pengaplikasian sulam Sashiko sebagai reka latarnya. Sashiko adalah teknik menjahit tradisional Jepang yang telah digunakan untuk menggabungkan beberapa lapisan kain sejak abad ke18. Penggabungan beberapa lapisan kain menggunakan Sashiko ini 
bertujuan untuk membuat pakaian lebih kuat dan tahan lama karena harga kain pada saat itu tidak tejangkau oleh para pekerja di sana. Jahit sulam Sashiko membentuk ornamen yang dapat dijadikan sebagai elemen estetis pada bidang kain.

\section{PROSES STUDI KREATIF}

Rancangan produk ini ditujukan bagi para wanita yang mengerti dunia fesyen dan peduli terhadap isu lingkungan. Pengaplikasian sulam Sashiko pada eksplorasi serat nanas ini diharapkan dapat mengangkat nilai guna dan nilai estetis serat nanas yang diperuntukan untuk produk fesyen.

Konsep dari pembuatan karya ini adalah mengetahui cara serta karya yang dapat dibuat menggunakan teknik reka struktur seperti tenun dan kertas untuk dijadikan sebagai produk fesyen dengan aplikasi sulam Sashiko sebagai reka latarnya sehingga dapat menambah nilai estetis untuk produk tersebut. Koleksi modern fesyen dengan tema Urban Tropical ini terinspirasi dari suasana taman kota, ketika bentuk alam yang organis bertemu dengan bentuk geometris yang struktural membuat tampilan karya ini memberikan kesan yang kasual dan dinamis.

Bahan yang digunakan dalam koleksi ini hanya menggunakan bahan serat alam dengan material utama yang berasal dari serat nanas serta bahan sutera organza, linen, sutera katun sebagai material pendukung. Sepintas koleksi pakaian ini terlihat tidak dapat digunakan (unwearable), namun dengan potongan pola yang sederhana digabungkan dengan unsur material kertas serat nanas ini menjadikan modern fesyen tidak hanya sebatas karya bernilai estetis namun memiliki nilai fungsi. Hal tersebut menjadikan penghubung yang sempurna antara seni dan fesyen.

Koleksi ini terbagi menjadi dua kategori, kategori pakaian berupa paper wear dan aksesoris fesyen berupa tas. Sasaran pengguna produk ini adalah wanitia berusia 21 - 35 tahun yang mengerti dunia fesyen, peduli akan lingkungan, berwawasan luas dan memiliki penampilan yang trendi. Salah satu hal penting dalam perancangan konsep dasar sebuah karya, diperlukan adanya moodboard untuk menentukan konsep yang akan dipresentasikan pada karya. Moodboard mampu memberikan suatu pencitraan terhadap suatu karya kepada publik sebagai bentuk ide dasar dari pembuatan karya.

Rancangan produk berupa produk fesyen yang sesuai dengan citra moodboard yang telah disusun dengan mengambil warna-warna hasil dari proses eksperimen warna menggunakan pewarna alam daun mangga dengan campuran pewarna alam tegeran. Pewarna alam daun mangga dan tegeran dipilih karena dapat menghasilkan warna kuning yang bervariasi. 


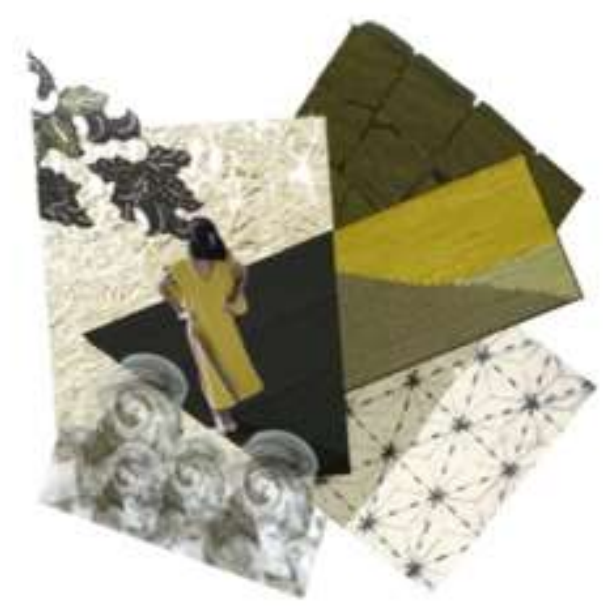

Gambar 1. Moodboard Urban Tropical (Adianti, 2016)



Gambar 2. Skema Warna Karya (Adianti, 2016)

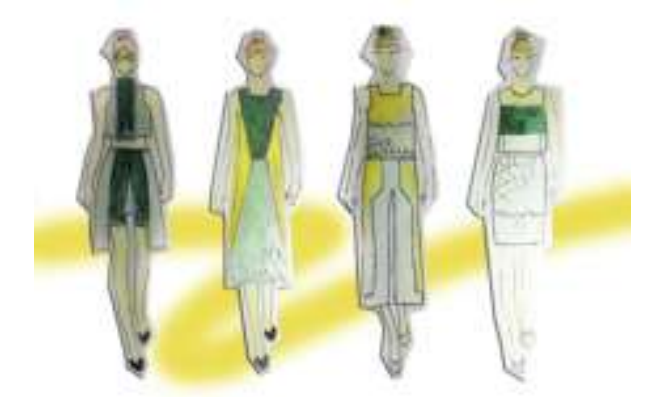

Gambar 3. Sketsa Produk Paper Wear (Adianti, 2016)
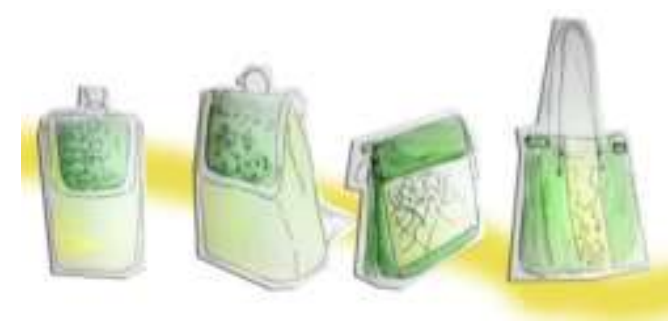

Gambar 4. Sketsa Produk Tas (Adianti, 2016)

Pada proses eksperimen dilakukan beberapa tahapan proses mulai dari pengolahan bahan baku utama serat nanas hingga proses eksperimen reka struktur dan reka latar. Setelah serat dibersihkan melalui proses scouring dan bleaching, proses pembersihan serat dilakukan pula dengan merendam serat yang telah dipotong pendek pada soda kostik untuk menghasilkan serat pulp agar jalinan serat mudah mengikat satu sama lain ketika proses pencetakan kertas. Setelah proses perendaman serat pada soda kostik, serat dibilas kemudian direndam pada larutan Bayclin untuk menghasilkan serat yang lebih bersih dan putih dengan takaran Bayclin dan air 1:10. Setelah itu serat dibilas dengan air bersih dan siap untuk dicetak menggunakan screen sablon.

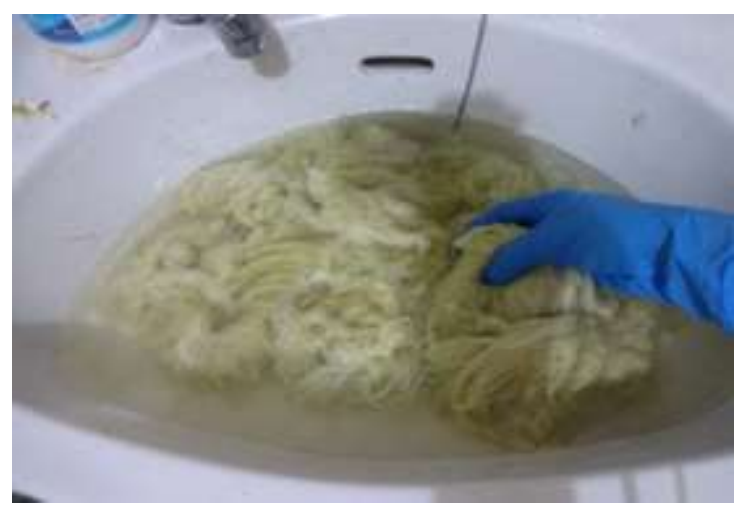

Gambar 5. Pembersihan dengan Larutan Bayclin (Adianti, 2016)

Pada proses pencetakan pulp kertas, serat dimasukan pada bak air untuk di saring menggunakan screen. Setelah serat disaring, serat yang terdapat pada saringan dicetak pada bidang papan triplek yang telah dilapisi kain untuk menghindari kertas yang menempel pada papan triplek saat kering. Setelah proses pencetakan, kertas pulp telah dicetak dijemur di bawah sinar matahari hingga kering. 


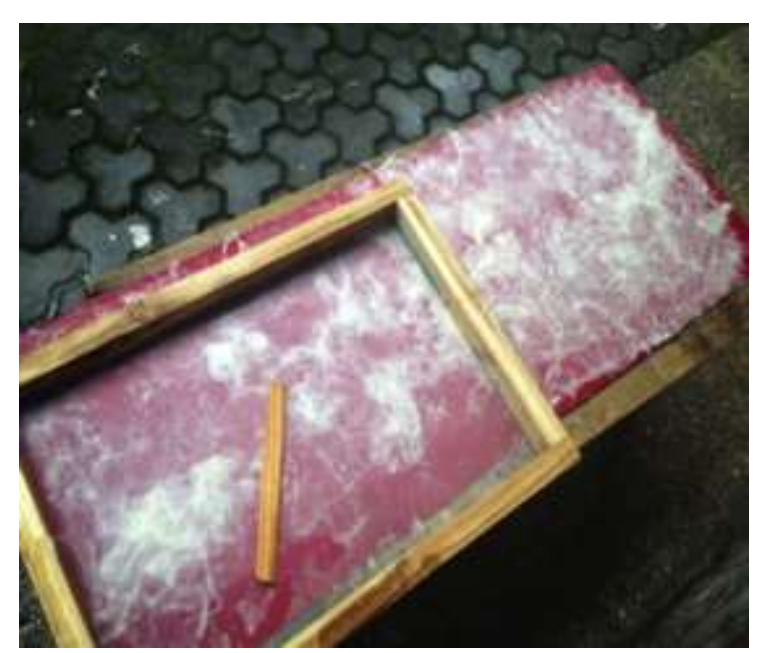

Gambar 6. Proses Pencetakan Kertas (Adianti, 2016)

Setelah dijemur kertas yang hampir kering ditambahkan perekat CMC (Carboxy Methyl Cellulose) dengan cara dioles dengan kuas yang dilarutkan pada air dengan perbandingan 1:5 untuk menghasilkan struktur kertas yang lebih kuat dan tidak mudah sobek. Proses selanjutnya yaitu pembuatan pola baju sesuai desain produk yang telah dibuat dan pembuatan pola sulam diatas kertas dan kain yang akan dijadikan baju menggunakan kertas karbon kemudian disulam serta kemudian dijahit.

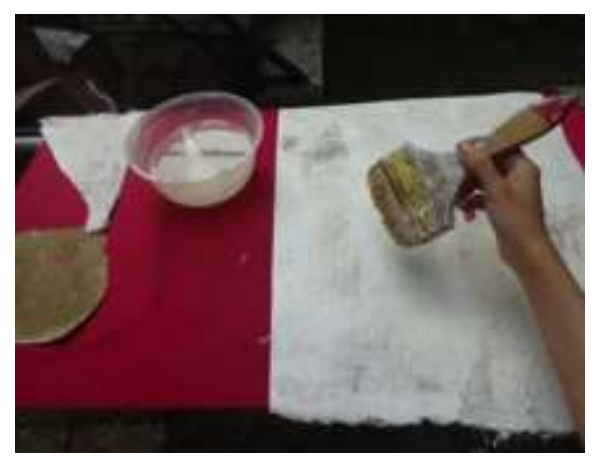

Gambar 7. Penambahan Perekat CMC Pada Kertas Setengah Kering (Adianti, 2016)

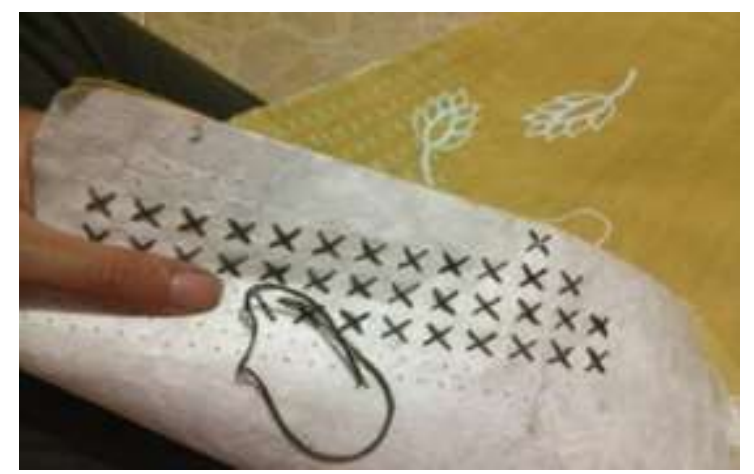

Gambar 8. Proses Sulam

(Adianti, 2016)

Berikut produk akhir yang dihasilkan dari proses eksperimen dan eksplorasi:

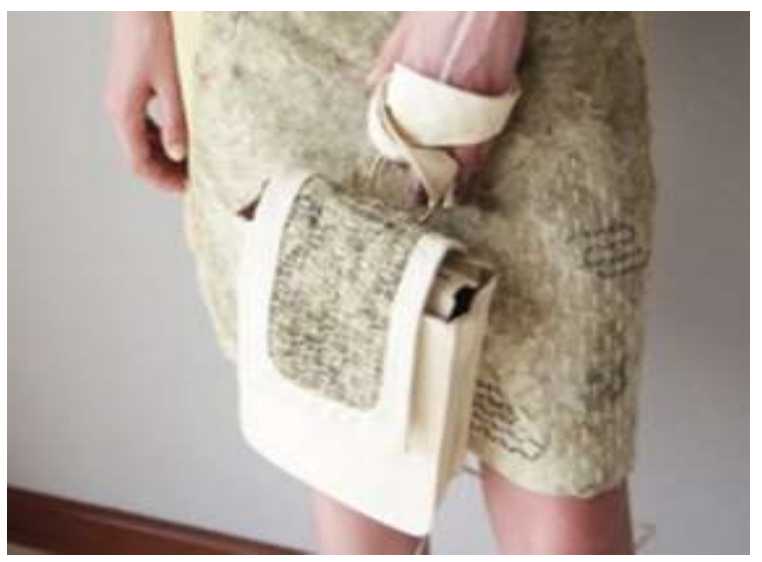

Gambar 9. Foto Produk Tas \#1

(Adianti, 2016)

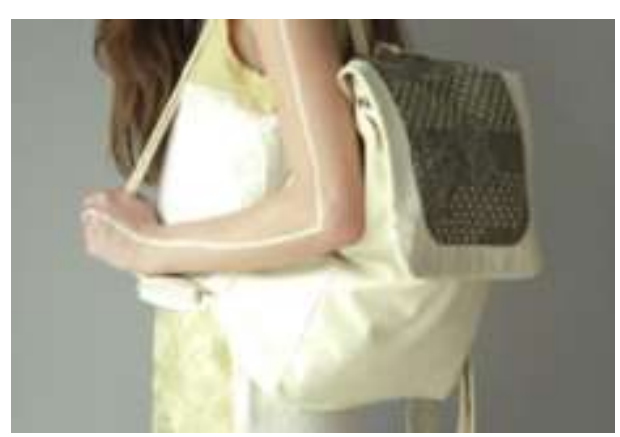

Gambar 10. Foto Produk Tas \#2 (Adianti, 2016) 


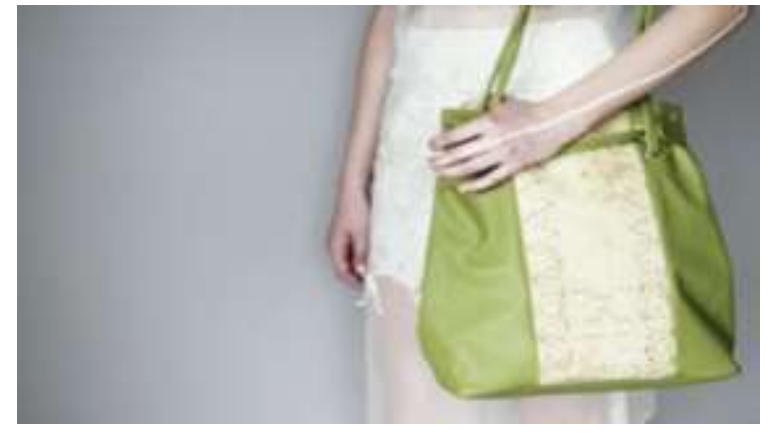

Gambar 11. Foto Produk Tas \#3 (Adianti, 2016)

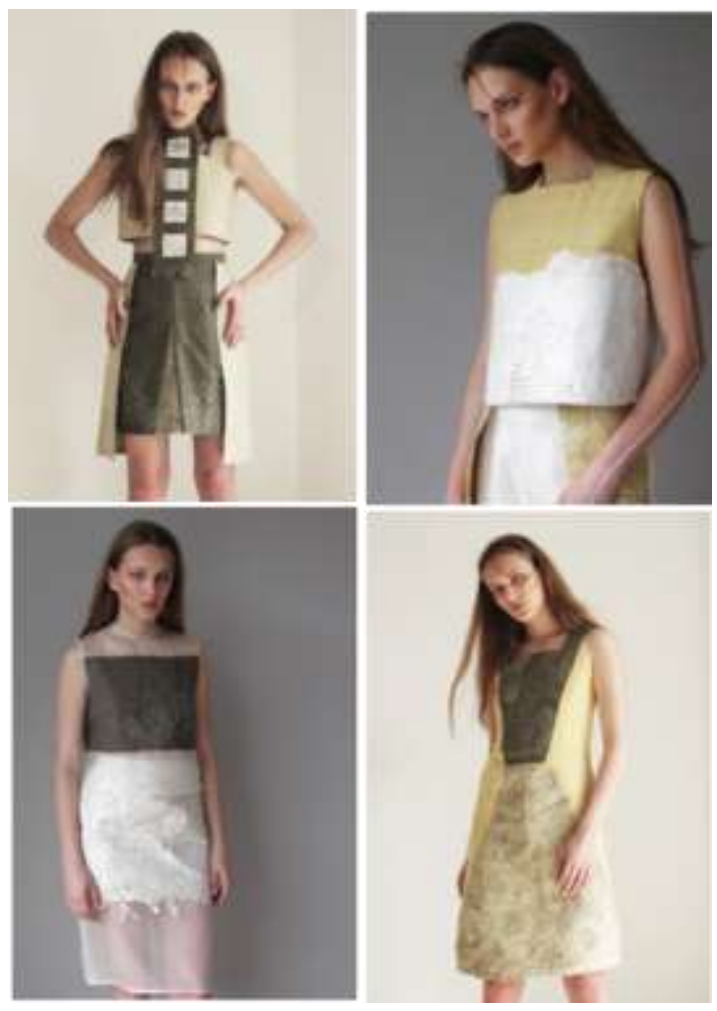

Gambar 12. Foto Produk Paper Wear (Adianti, 2016)

\section{KESIMPULAN}

Berdasarkan dari hasil eksplorasi, data-data serta produk akhir dari penelitian ini, maka didapatkan kesimpulan dari permasalahan penelitian, yaitu sebagai berikut : a. Tanaman nanas (Ananas comosus), memiliki potensi sebagai bahan baku tekstil karena bagian serat daun tanaman tersebut yang berbentuk filamen, ringan dan memiliki ukuran yang kecil.

b. Serat tanaman nanas memiliki potensi sebagai bahan baku tekstil karena, dapat dijadikan benang melalui proses pemintalan. Selain itu, serat nanas memiliki bentuk serat berupa filament, tanpa dipintal terlebih dahulu serat tanaman tersebut dapat langsung digunakan sebagai benang karena bentuknya yang sudah halus seperti benang. Tanpa mencampur serat tersebut dengan material lain, serat tanaman nanas dapat digunakan langsung sebagai bahan baku tekstil sebagai benang pakan untuk tenun maupun sebagai bahan pulp kertas. Baik serat yang dipintal maupun yang tidak, serta baik serat yang melalui proses scouring, bleaching dan softening maupun serat yang tidak melalui proses tersebut dapat digunakan sebagai material tekstil dengan teknik tenun dan teknik kertas.

c. Teknik tenun adalah teknik yang dapat digunakan untuk mengolah dan menghasilkan bahan tekstil berbahan baku serat alam. Namun apabila ditinjau di pasaran bahan tekstil 
serat nanas dengan teknik tenun sudah cukup banyak dipasaran terlebih banyaknya orang mengetahui nama kain nanas sebagai nama pasar bukan kain yang berasal dari serat nanas, maka penelitian ini lebih menfokuskan bagaimana mengembangkan bahan baku tekstil bermaterial serat nanas yang masih jarang ditemukan di pasaran. Maka dari itu teknik kertas lebih dikembangkan untuk dijadikan produk agar menghasilkan bahan baku tekstil yang berbeda dari yang ada di pasaran.

Dari ketiga kesimpulan tersebut, terdapat beberapa saran serta evaluasi yang berkaitan dengan penelitian ini, yaitu :

a. Perlu dilakukan studi lebih lanjut untuk lebih mengoptimalkan kekuatan struktur serat tanaman nanas dengan teknik kempa dan kertas (non-woven) pada proses finishing sebagai bahan baku tekstil. Terutama pada proses pengolahan cetak lembaran serat agar menghasilkan lembaran dengan ketebalan yang sama.

b. Proses pembusukan dan fermentasi serat nanas untuk dijadikan bahan kertas dapat dilakukan secara cepat untuk produksi masal dengan cara merendam serat nanas dengan soda kostik, namun cara tersebut menghasilkan limbah kimia. Proses lainnya dapat dilakukan dengan cara fermentasi alami menggunakan enzim, namun proses tersebut membutuhkan waktu yang cukup lama serta membutuhkan penelitian lebih lanjut terhadap variabel air, cahaya, dan suhu yang digunakan.

c. Merujuk pada hasil penelitian berupa eksperimen dan eksplorasi yang telah dilakukan selama penelitian, tidak menutup kemungkinan tekstil berbahan baku serat nanas digunakan sebagai material untuk membuat produk yang berupa bahan tekstil untuk interior, tidak hanya sebatas pada busana maupun produk fesyen lainnya.

\section{DAFTAR PUSTAKA}

Bangun, Sem Cornelyus dkk.

(2014), Seni Budaya SMK/ MA/ SMA/ MAK Kelas IX Semester 1, Kementerian Pendidikan dan Kebudayaan, Jakarta.

Briscoe, Susan.

(2004), The Ultimate Sashiko Sourcebook. David \& Charles, United Kingdom.

Dahlan, Ir. R.E.

(1982), Petunjuk Praktek Pembuatan Kain 2, PT. Melton Putra, Jakarta. 
Destiarmand, Achmad H.

(1999), Bentuk dan Gaya, Program

Studi Kriya, FSRD ITB. Bandung.

Fogg, Marnie.

(2014), Why You Can Go Out Dressed Like That. Thames \& Hudson, United Kingdom.

Haldani, Achmad.

(1999), Sejarah dan Gaya Dalam Fesyen. Diktat Kuliah FSRD ITB. Bandung.

Hidayat, Pratikno.

(2008), Teknologi Pemanfaatan Serat Daun Nanas Sebagai Alternatif Bahan Baku Tekstil, Teknoin, Volume 13, Nomor 2, Desember 2008.
Jumaeri dkk.

(1977), Pengetahuan Barang Tekstil, Institut Teknologi Tekstil, Bandung.

Sanyoto, Drs. Sadjiman Ebdi.

(2009), Nirmana: Dasar-dasar Seni dan Desain, Percetakan Jalasutra, Yogyakarta.

Rizaldi, Nanang.

(1992), Pengaruh Perubahan Desain Tekstil Terhadap Perkembangan Mode dan Kecenderungan Pasar, Thesis Pascasarjana Seni Rupa dan Desain, FSRD ITB, Bandung

Stout, Evelyn E.

(1960), Introduction To Textile, John Wiley \& Sons, Inc, USA. 